\title{
ANÁlise DE VIABILIDADE DE UM PLANO DE NEGÓCIO PARA SOLDAGEM DE TUBULAÇÕES DE PREPARAÇÃO E SUSTENTAÇÃO DE POÇOS EM ÓLEO E GÁS
}

Eliete Pereira Barbosa Kajihara (epbkajihara@gmail.com) - Escola Politécnica, Universidade de São Paulo.

Paulo Carlos Kaminski (pckamins@usp.br) - Escola Politécnica, Universidade de São Paulo.

\begin{abstract}
RESUMO
O trabalho tem como objetivo propor o projeto de uma fábrica de soldagens circunferenciais em tubos de 20" a 46" de diâmetro externo, usados na construção de poços de petróleo, atendendo aos requisitos da especificação Recommended Practice DNV-RP-C203, Fatigue Design of Offshore Steel Structures, que contempla a técnica de esmerilhamento do pé da raiz da solda, posterior controle de espessura de parede dos tubos, e recomendações à fadiga. Para atender a estes requisitos, o detalhamento deste projeto inclui a elaboração da planta, instalação da unidade fabril, quantidade de funcionários e áreas envolvidas, descrição do processo produtivo, tecnologias de fabricação, vendas de produtos manufaturados, estoque e manutenção. A metodologia utilizada baseou-se em levantamentos bibliográficos, livros, sites, consultas técnicas e comerciais, e um estudo de caso sobre uma instalação com dados concretos. O negócio demanda complexidade e investimentos, e embora a estagnação atual do mercado de óleo e gás, devido à baixa do preço do barril de petróleo, não favoreça um investimento inicial de aproximadamente $R \$ 4.000 .000,00$ com uma taxa de retorno prevista em 65 meses num cenário otimista, para produzir 130 tubulações mensais, o estudo visa elevar o país no âmbito tecnológico e estender-se a outras indústrias do setor energético.
\end{abstract}

Palavras chave: Tubulações; soldagem; modelo de negócio; poços; óleo e gás

Área: Gestão de Projetos de Desenvolvimento de Produtos e Serviços

\section{INTRODUÇÃO}

\subsection{Histórico}

O Petróleo é conhecido desde os primórdios da civilização com aplicações diversas como material de liga nos Jardins Suspensos da Babilônia, impermeabilizante de embarcações e embalsamento dos mortos, além de aplicações nas indústrias farmacêuticas e nas iluminações das residências, no século 18 (SERPUB, 1976).

$\mathrm{Na}$ segunda metade do século XIX foram deixados de lado os métodos primitivos de perfuração de poços para dar lugar a perspectivas de perfurar poços mais profundos. $\mathrm{O}$ americano Edwin Drake, foi o responsável por introduzir este conceito através de um equipamento tipo bate-estaca por sistema de percussão, que abriu o primeiro poço considerado profundo com apenas 21 metros na Pensilvânia em 1859. Porém antes de alcançar esta profundidade Drake se viu diante do problema de desmoronamento de paredes, que o fez colocar em prática o revestimento da cavidade com tubos de ferro, prática ainda em uso nos dias atuais (NEIVA, 1993). 


\subsection{Objetivo}

A partir de 2010 várias das companhias internacionais de perfuração que chegaram ao Brasil solicitaram que os projetos de juntas expostas no fundo do mar, quando em regime de fadiga, deveriam atender a $R P D N V-R P-C 203$, que orienta como devem ser realizados os projetos, fabricações e inspeções para estas tubulações soldadas com $o$ intuito de reduzir a concentração de tensões nas soldas. O objetivo aqui é propor um modelo de negócios de soldagem, especificamente para soldas circunferenciais de tubulações rosqueadas, acima de 20 " de diâmetro, utilizadas como revestimentos e sustentação de poços e a viabilidade desta proposta para o mercado de óleo e gás. Isto requer que empresas ou equipes especializadas devam ser criadas com foco exclusivo neste tipo de serviço. Este plano de negócio será criado, considerando uma pesquisa que mostre a real necessidade deste trabalho, a espiral de projeto e o ciclo de produção e projetando os recursos necessários para tal, que irão desde pessoas, espaço, dispositivos até a logística.

\subsection{Estruturação do negócio}

Com o intuito de definir uma sequência de processos necessários à implementação da empresa, e visando o planejamento e organização das etapas evitando desvios e custos de retrabalho, foi elaborado o fluxograma na figura 1, o qual sincroniza a metodologia de elaboração deste trabalho junto as necessidades de demanda de execução operacional para implementar a empresa e atender à necessidade dos clientes, ou seja, este fluxograma é originado a partir da solicitação do cliente, estruturando os processos sequencialmente para permitir a viabilidade do negócio. 
Figura 1 - Fluxograma de Processos

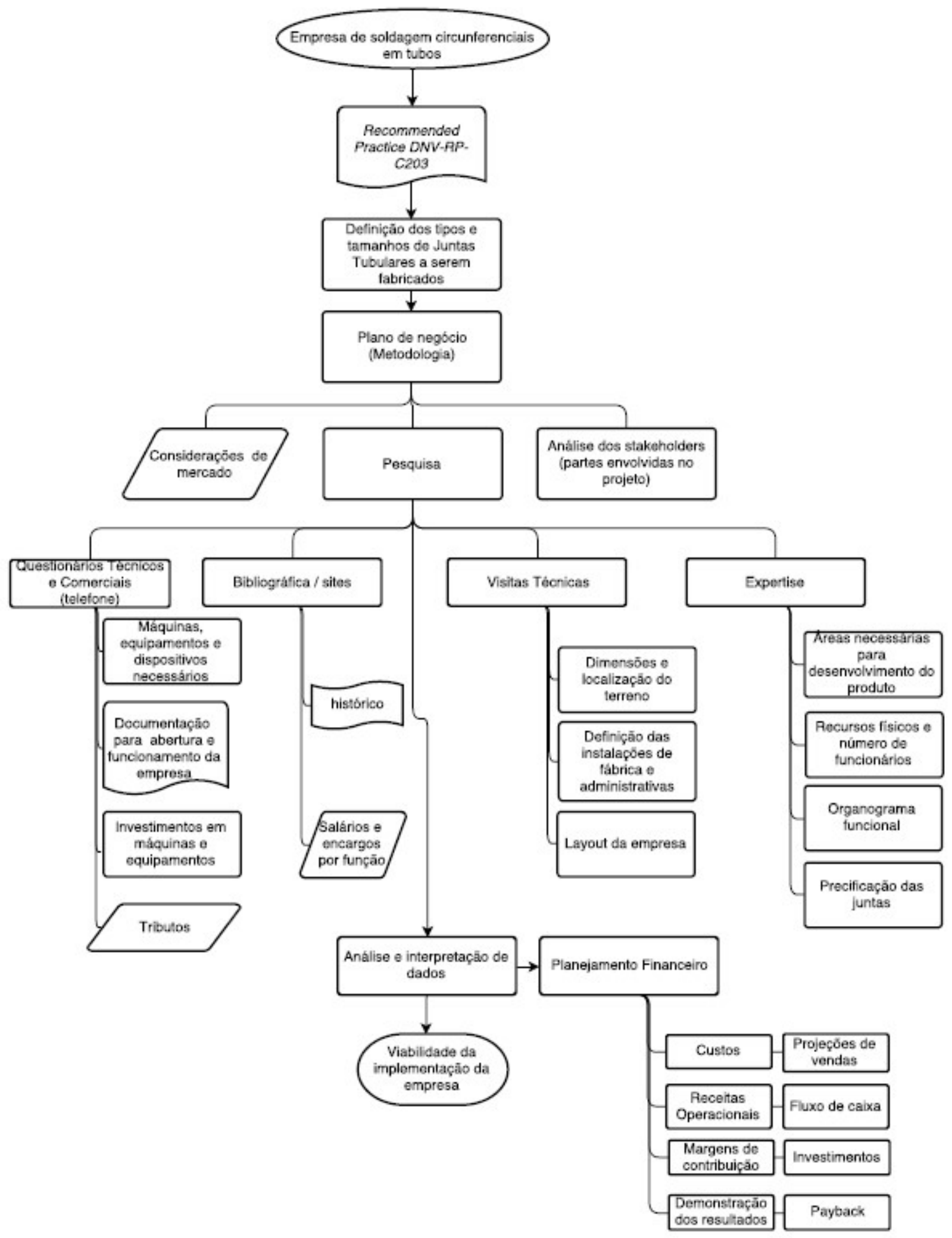

Fonte: Própria 


\section{DADOS DO PRODUTO}

\subsection{Juntas tubulares e suas funções}

Os componentes relevantes durante a preparação de um poço submarino são os condutores e revestimentos, que na terminologia de perfuração de poços, são seções de tubos num campo petrolífero conectados para serem descidos em um poço e cimentados com a função básica de sustentar as formações perfuradas pela broca. Tratam-se de tubulações cujos diâmetros podem variar de 7" a 36". Os revestimentos possuem funções como prevenir o desmoronamento das paredes do poço, evitar a contaminação da água potável dos lençóis freáticos mais próximos à superfície, permitir o retorno do fluído de perfuração à superfície, prover meios de controle de pressões dos fluídos, sustentar os equipamentos que carregam estas tubulações (sistema de cabeça de poço), sustentar outra coluna de revestimento, entre outras. Os condutores, são a primeira fase de revestimento de poço, assentado a pequenas profundidades $(10 \mathrm{~m}$ a $50 \mathrm{~m})$, com a finalidade de sustentar sedimentos superficiais não consolidados. (THOMAS, 2001). Os condutores e os revestimentos são formados por juntas (segmentos de tubos) que são rosqueados. A conexão das juntas é feita a bordo da sonda, no "drill floor" (piso da sonda), sendo instaladas através dos alojadores de alta e baixa que compõe o sistema de cabeça de poço. Na figura 2 são apresentadas as fases de condutores e revestimentos. Há um nicho de mercado a ser estudado e possivelmente implementado para que os processos atendam as normas aplicáveis.

Figura 2 - Esquema de revestimento de poços

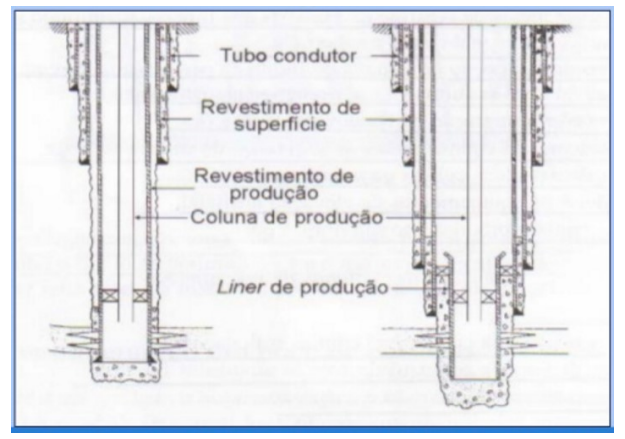

Fonte: Thomas, 2001

Estas seções de tubo são chamadas de juntas tubulares, como aparecem nas figuras 3 e 4, e são tipicamente de comprimento de cerca de 12 metros (40 pés).

Figura 3 - Junta Intermediária

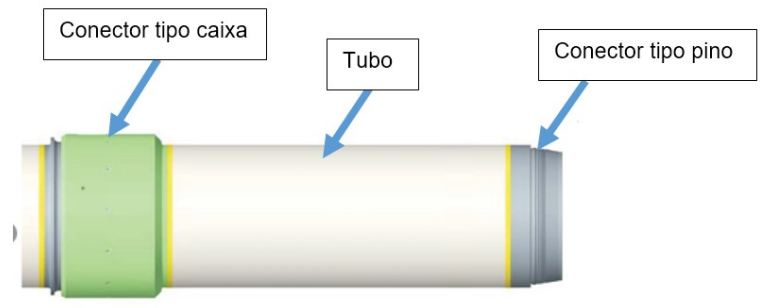

Fonte: Própria
Figura 4 - Condutores de Revestimento

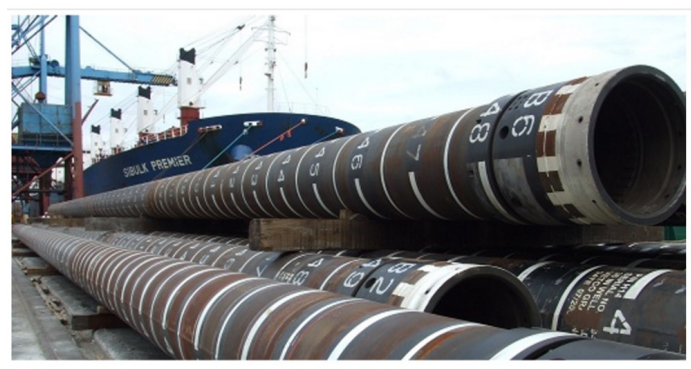

Fonte: http://www.intermoor.com/

A geometria das juntas e seus processos de soldagem criam tensões elevadas em pontos isolados da região soldada. Estas tensões são importantes na análise de carregamentos variáveis que agem sob a plataforma, provenientes de ondas, vento e correntes marítimas. Tais cargas causam flutuações no nível de tensões na junta tubular, possibilitando nucleação e 
propagação de trincas, podendo levar a uma falha estrutural da junta por processo de fadiga (CARDOSO, 1999).

\subsection{Contextualização de fadiga e a especificação DNV-RP-C203}

Define-se como fadiga o acúmulo de danos causados pela exposição de um componente mecânico a carregamentos alternados (cíclicos), podendo levar o material à falha sob carregamentos consideravelmente inferiores a seu limite de resistência (algumas vezes mesmo antes de se atingir o limite de escoamento), estas falhas, por sua vez, diferem consideravelmente das falhas sob carregamentos estáticos (FONSECA, 2014).

Conforme definição pela ASTM, a fadiga é um processo de alteração estrutural permanente, progressivo e localizado. Assim, este fenômeno consiste na acumulação de dano num material sujeito a tensões e deformações cuja intensidade é variável, resultando eventualmente no colapso da estrutura. As cargas de fadiga podem ser devidas ao tráfego, vento, água do mar, sismos ou qualquer outra ação de carácter não permanente (MARTINS, 2013).

A DNV RP C203 apresenta recomendações relacionadas à fadiga baseada em testes de fadiga e mecânica da fratura, para assegurar que a estrutura tenha uma vida à fadiga adequada, e é válida para estruturas de aço com tensão de escoamento menor que $500 \mathrm{MPa}$ na água do mar com proteção catódica ou com corrosão livre. O esmerilhamento do pé da raiz da solda, contemplado na DNV RP C203, é uma técnica muito utilizada para o aumento da vida em fadiga, através da redução do efeito de concentração de tensões nesta região, possibilitando a remoção de pequenos defeitos presentes na raiz da solda. Conforme a DNV RP C203, o cálculo de fadiga e o comportamento das soldas é conhecido e há regras que apresentam curvas S-N para diferentes juntas soldadas que são obtidas a partir de ensaios de fadiga e levam em consideração fator de concentração de tensão. As Soldagens em juntas tubulares (revestimentos e condutores) são normalmente realizadas em chanfros simétricos por solda de topo e circunferenciais. A DNV RP C203 determina ainda que a remoção do excesso de solda deve ser feita por esmerilhamento, para reduzir as concentrações de tensões na região soldada e atentando para que não haja redução de espessura de parede do tubo.

\section{PLANO DE NEGÓCIO}

\subsection{Conceito do plano de negócio}

As empresas necessitam de planejamento para conseguir manterem-se no mercado, evitando que elas iniciem suas atividades sem rumo definido, somente pensando em sua atuação prática, sem uma análise prévia. O plano de negócios é o primeiro passo para o empreendedor iniciar seu empreendimento, pois irá auxiliá-lo a ter uma visão atual e futura, inscrita no papel (FOLLMAN, 2009).

Com este plano em mãos, toda a estrutura de funcionamento da empresa fica definida, através da elaboração de um planejamento com base na necessidade de projeto e fabricação, e demanda de atendimento e fornecimento aos clientes.

Este plano de negócio, apresenta a implantação de uma empresa de soldagem em tubos de grande diâmetro na região de Macaé, onde encontra-se grande parte das companhias de óleo e gás que utilizam estes equipamentos, mas ainda pretende-se atender ao mercado "Onshore" (em terra) onde a maioria das companhias estão localizadas no Nordeste do Brasil. Visando atender aos requisitos da especificação DNV RP C203, mas respeitando também os requisitos de soldagem de outras especificações como ASME, API 5L, API 1104. 
Esta necessidade de abertura de uma empresa deste tipo, é devido a crescente aumento de critérios para a solda de tubos x conectores, tubos x tubos, tubos x "landing sub" (camisa para assentamento) em tubulações que podem ser expostas numa situação de criticidade a um momento fletor que leve o revestimento/ condutor a trabalhar no regime plástico e o levando a uma ruptura, causando uma situação de risco, ou de dano ao meio ambiente no fundo do mar e colocando vidas em risco.

Macaé é um pólo de óleo e gás, e também a região que abrange o pré-sal e onde concentra a maior parte dos clientes deste tipo de negócio. Garantindo assim uma estrutura adequada para a implantação desta empresa e a viabilização do negócio após esta análise.

\subsection{Considerações sobre o mercado}

A importância ao efetuar a análise de mercado é retratar o cenário atual para a criação desta empresa na região de Macaé num contexto de crise a qual se encontra o Brasil nos últimos três anos e principalmente para a área de óleo e gás que se encontra estagnada. Há uma perspectiva de reação do mercado em 2018, o que criaria espaço para a abertura da empresa já num momento de retomada do mercado, ou seja, trata-se de um investimento suportado por ações de melhoria na economia.

Enquanto isto, há tempo para formar uma carteira de clientes robusta e encontrar parcerias com novas empresas de perfuração diante de uma possível abertura de mercado criado pela instabilidade em torno da Petrobras.

Paralelamente uma análise de fornecedores com negociação de preços e prazos, e um plano financeiro capaz de interpretar o tempo de retorno de capital investido, as projeções de receitas, despesas e custos, verificando sua viabilidade e potencial de rentabilidade. Após cinco anos sem rodadas de licitações para exploração e produção de petróleo e gás natural e com grandes desafios no pré-sal por serem conquistados, o Brasil retomou o processo licitatório. Esse período de inatividade em termos de licitações foi interessante para que a Petrobras (empresa na qual o governo detém $51 \%$ de participação) buscasse sustentação financeira para desenvolver a região de Libra, para iniciar a fase de desenvolvimento da produção, minimizando futuramente a fase de altos investimentos nos campos mais onerosos dos primeiros blocos do pré-sal. Porém, a produção projetada estará acima dos níveis atuais, e a indústria brasileira que fornece bens e presta serviços para a fase de desenvolvimento de produção terá aumentado seu nível de maturidade. Do ponto de vista legal, a retomada das licitações por parte da ANP motivou uma revisão no modelo de regulamentação da exploração e produção petrolífera. As demais áreas com potencial de óleo e gás - cerca de $97 \%$ das bacias sedimentares brasileiras. A criação de políticas corretas que incentivem o mercado local é o que dará suporte para o surgimento de fornecedores capacitados a ofertar produtos e serviços ao mercado brasileiro (ERNST \& YOUNG, 2014).

Porém após 2015, com a queda do preço do petróleo no mundo e a crise de corrupção que a Petrobras vem enfrentando, estima-se que a queda nas receitas irá levar as empresas de exploração e produção a reduzir o fluxo de caixa disponível para reinvestimentos. Com a queda nos gastos, as companhias de serviços para campos petrolíferos e empresas responsáveis pelo transporte do produto devem começar a sentir esse obstáculo. (MOODY's, 2016).

\section{PARQUE FABRIL}

O espaço para a montagem deste arranjo físico para compor este Parque industrial deve acomodar as áreas administrativas e fabris, além de prover um amplo espaço para 
movimentação de cargas entre as áreas de manufatura e facilitar a logística de entrada e saída de equipamento. Adicionalmente, cabe a esta área conter os serviços comuns como: abastecimento de energia elétrica, abastecimento de água com diversos tipos de tratamento, serviço de vigilância, recepção, tratamento de águas residuais, e sistemas de manuseio e transporte. Assim, foi definido um terreno no bairro de Cabiúnas, localizado no polo industrial de Cabiúnas a $14 \mathrm{~km}$ do centro de Macaé no estado do Rio de Janeiro.

O terreno escolhido possui $18.000 \mathrm{~m}^{2}$, e a princípio será alugado. Por se tratar de um polo industrial, muitos recursos poderão ser rateados entre outros condôminos. Também está relativamente distante de áreas urbanas para reduzir o impacto ambiental e social dos usos industriais.

Os principais consumidores deste tipo de serviço são as empresas de Perfuração no setor de óleo e gás, tais como: Petrobras, Shell, GE, Drill-Quip, BP, BG, Devon, Repsol, Queiroz Galvão, Exxon, Statoil, Schlumberger, Halliburton, Sonangol, Eni, Chevron, Hess, Pemex, Total, Starfish, Maersk e outras. Todas estas empresas possuem base e operam em Macaé. O posicionamento da empresa próximo aos fornecedores tem relação direta com o preço final dos equipamentos a serem ofertados, aumentando a competitividade junto aos concorrentes.

\section{INSTALAÇÃO FABRIL}

Considerou-se um parque fabril nas proximidades de Macaé, no Rio de Janeiro, um quadro de funcionários com mão de obra qualificada para construir juntas tubulares de diversos diâmetros e comprimentos e também projetos especiais de tubulações de acordo com as solicitações dos clientes. A área de fabricação deve atender os requisitos de segurança e garantir a rapidez e qualidade dos equipamentos produzidos com diferentes tamanhos e complexidades. Nesta instalação fabril são definidas as áreas abaixo como fundamentais para a execução do produto para este negócio:

- Recebimento, Matéria-prima, armazenamento e almoxarifado;

- Área de Soldagem e Preparação;

- Planejamento e Controle de Produção;

- Revestimento;

- Máquinas, Equipamentos e Dispositivos. Neste item são considerados essenciais em atendimento a especificação DNV, a aquisição dos equipamentos mostrados nas figuras 5 e 6 ;

- Controle de Qualidade;

- Montagem e teste, e espaço destinado a expedição do produto;

Figura 5 - Carrinhos para manuseio de tubos de grande porte

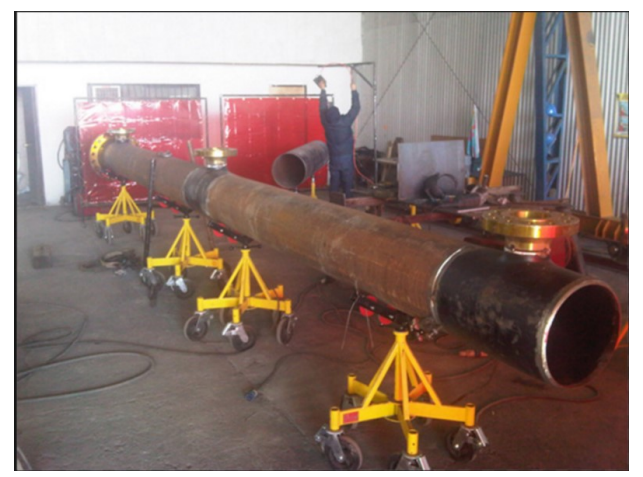

Fonte: www.soldasbrasil.com.br/cavalete-apoio-movimentacao-tubulacoes.php 
Figura 6 - Dispositivos de esmerilhamento interno e externo de tubos de grande porte
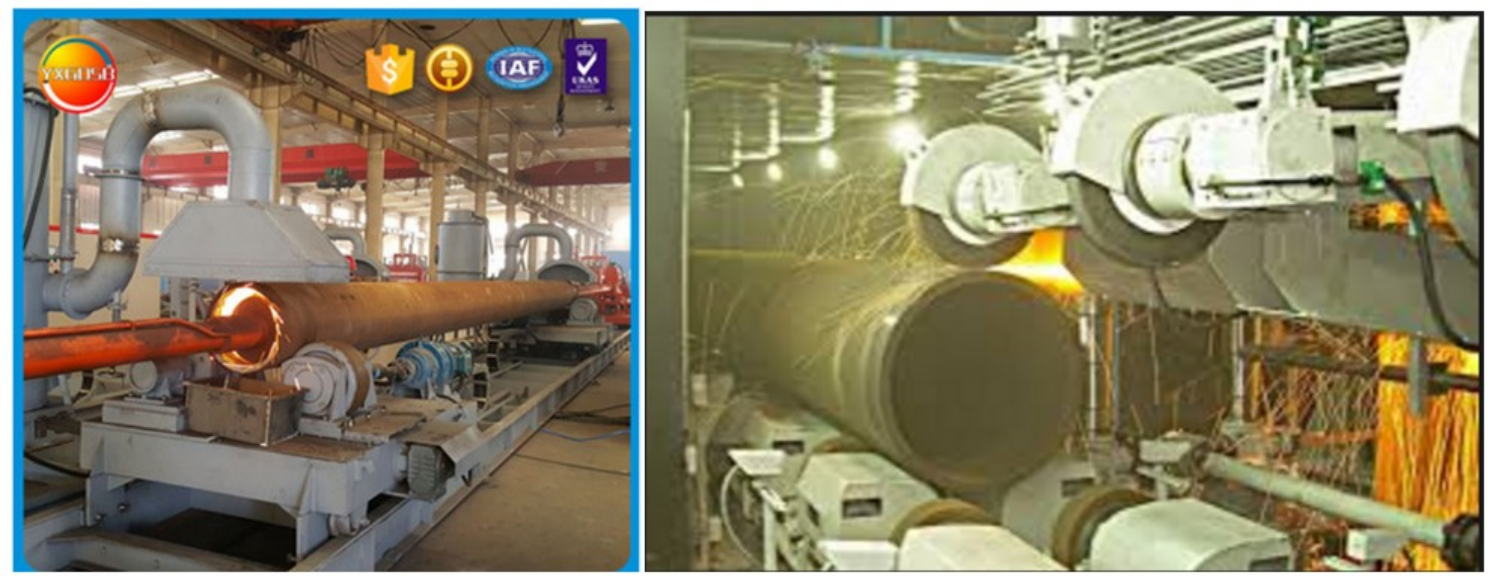

Fonte: https://dezhouyxgd.en.alibaba.com

\section{INSTALAÇÃO ADMINISTRATIVA}

Nesta instalação administrativa, as áreas abaixo foram consideradas mínimas para o desenvolvimento de produtos para este negócio:

- Vendas;

- Gerenciamento de Projetos;

- Engenharia;

- Tecnologia da Informação;

- Cadeia de Suprimentos;

- Recursos Humanos;

- Saúde, Segurança e Meio ambiente (SSMA);

- Financeiro e Jurídico.

\section{PROCEDIMENTO METODOLÓGICO}

A metodologia utilizada traz um levantamento bibliográfico e documental em livros e sites relacionados ao assunto, também de pesquisa aplicada com base em consultas técnicas e comerciais a representantes de empresas do ramo, e ao conhecimento técnico adquirido durante anos de trabalho em empresas ABB Óleo e Gás em Osasco, General Eletric Óleo e Gás em Jandira e General Eletric em Macaé.

\subsection{Coleta de dados}

A coleta de dados, utilizou técnicas de pesquisas qualitativas estruturadas, definição de local para o arranjo físico da empresa, busca de tributações financeiras e demandas envolvidas. As referências bibliográficas utilizadas para a compreensão das especificações que causam impacto direto em engenharia, gerando a necessidade de maquinário, inspeções e outros atributos necessários para o atendimento aos requisitos dos clientes. Visitas técnico-comercial a empresas, para obtenção de informações comerciais e jurídicas, além de entrevistas por telefone com pessoal das áreas correlatas para obtenção de informações de mercado.

\subsection{Análise e interpretação de dados}

A partir das respostas obtidas nas pesquisas, o dimensionamento do negócio foi modelado. Considerando o alto investimento em recursos físicos e humanos, e aos altos tributos e risco 
que o negócio oferece, foi necessário considerar uma produção inicial de 130 juntas. Em função deste requisito pré-determinado definiu-se uma área para armazenamento de tubos e conectores para a fabricação mensal destes itens com um galpão industrial de aproximadamente $700 \mathrm{~m}^{2}$ e uma área total de armazenamento de $3.000 \mathrm{~m}^{2}$ total. A área de chão de fábrica com uma área aproximada de $2000 \mathrm{~m}^{2}$, e por fim $400 \mathrm{~m}^{2}$ de área administrativa para atender a demanda do negócio.

Também foram verificadas todas as licenças e tributos e total de funcionários para a abertura e funcionamento desta empresa. Desta demanda também se chegou ao número de funcionários e máquinas para atendimento da demanda.

\section{ANÁLISE DE VIABILIDADE PARA CRIAÇÃO DA EMPRESA}

Grande parte das empresas que fazem este serviço no Brasil não são especializadas no processo de soldagem, normalmente são fabricantes do produto principal que suportam as juntas, e por isto não atendem integralmente os cálculos, critérios de segurança, requisitos de inspeção e controle, e não há um órgão certificador que audite e inspecione o processo de soldagem nas empresas conforme esta especificação. Aqui foram considerados e analisados todos os itens abaixo para tornar o negócio factível.

- Documentos para a abertura e funcionamento da empresa;

- Tributos, salários, encargos e precificação das juntas;

- Recursos em pessoas, investimentos em máquinas e equipamentos;

- Layout (planta) da empresa;

- Plano financeiro (Custos fixos e variáveis, projeções de vendas, receitas operacionais, fluxos de caixa, margem de contribuição, investimento, demonstração dos resultados nos cenários, otimista, realista e pessimista, e por fim Payback);

Uma análise de Payback, foi realizada para definir o tempo de retorno de investimento, conforme apresentado na tabela 1 :

Tabela 1 - Retorno de Investimento

\begin{tabular}{|l|l|l}
\hline 220 meses (pessimista) & 119 meses (realista) & 65 meses (otimista)
\end{tabular}

\section{Fonte: Própria}

Embora os tempos de retorno de investimento tenham sido calculados, no mercado de óleo e gás todos os valores são diretamente afetados pelo preço do barril do petróleo que atualmente (2017) está em torno de US\$ 55,00, com fortes oscilações. Para que qualquer empreendimento neste ramo obtenha sucesso no Brasil é necessário que o preço mínimo do barril do petróleo esteja em torno de US\$ 60,00 estável.

Considerando uma taxa de mercado de $15 \%$ sobre o investimento inicial de $\mathrm{R} \$ 3.377 .700,00$ foram calculadas taxas de VPL (Valor Presente Líquido) e TIR (taxa Interna de Retorno) para os mesmos cenários, conforme abaixo:

Tabela 2 - Monte Carlo (simplificada)

\begin{tabular}{|l|l|l|}
\hline Realista & Otimista & Pessimista \\
\hline VPL $=3.202 .264,08$ & VPL $=8.324 .325,16$ & VPL $=182.671,77$ \\
\hline TIR $=17,01 \%$ & TIR $=41,43 \%$ & TIR $=1,09 \%$ \\
\hline
\end{tabular}

Fonte: Própria 
Ou seja, a implementação desta empresa no momento atual encontra-se no cenário pessimista. A análise foi realizada por trimestre durante um ano, se a projeção para os demais anos for realizada conforme o mercado atual, a taxa de retorno não será viável.

\section{CONCLUSÃO}

Este negócio envolve alta complexidade, os preços praticados no mercado quando comparados aos tributos, folha de pagamento de funcionários e investimentos em máquinas e equipamentos, ainda é um negócio lucrativo do ponto de vista financeiro e técnico.

Porém, o investimento inicial para uma fábrica que precisa manufaturar 130 juntas por mês, sendo estimada uma receita de aproximadamente 2 milhões por mês, e cuja despesa com construção da planta, aluguel de terreno, funcionários, materiais e máquinas e equipamentos, e despesas fixas mensais (água, luz, telefone, internet, etc.) durante a instalação se aproxima de um investimento de 10 milhões. Entretanto com a baixa do preço do barril de petróleo, o esfriamento do mercado, e a crise mundial que não traz expectativas favoráveis conforme últimos relatórios da ANP, não garantem que uma estrutura tão robusta, e necessária para o atendimento desta fatia do mercado possam aguardar mais do que um ano e meio a retomada da economia, e nem tem pouco encontram-se investidores neste momento para dispender desta quantia com tão poucas visões de retomada do mercado nos próximos 4 anos.

Infelizmente, a construção do ponto de vista de investimentos de acordo com o mercado torna a criação do negócio inviável.

\section{REFERÊNCIAS BIBLIOGRÁFICAS}

CARDOSO, A. A., Redes neurais artificiais na avaliação de Concentração de Tensões em juntas soldadas, Tese de doutorado submetida ao corpo docente da Escola Politécnica da Universidade de São Paulo, São Paulo, 1999;

DNV-RP-C203, Fatigue design offshore steel structures, 2011;

ERNST \& YOUNG, Perspectivas para a indústria de petróleo e gás no Brasil, imp. 2014;

FOLLMAN, I., Plano de negócio para implantação da filial da empresa Guindasul Comércio de Guindastes Ltda na cidade de Chapecó/ SC, Trabalho de Conclusão de curso para obtenção do título de Bacharel em Administração da Univali, Biguaçu, 2009;

MARTINS, A. F. P. M., Análise de fadiga em juntas de tensão em estruturas offshore, Dissertação para obtenção do título de mestre em Engenharia Civil com especialização em estruturas na Universidade do Porto, Portugal, 2013;

MOODY's, Investors Service, Global Oil and Gas Industry: Lower Oil Prices in 2015 Reduce E\&P Spending and Raise Risk for OFS Sector, Disponível em: https://www.moodys.com. Acesso em 29 de Set, 2016;

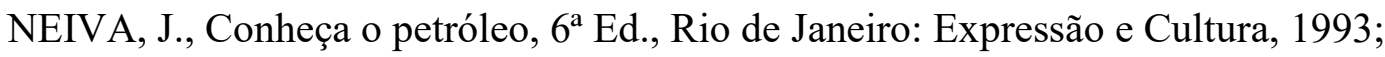

SERPUB, Serviço de relações públicas, O Petróleo e a Petrobras, catálogo da Petrobras, imp. 1976;

THOMAS, J.E., Fundamentos da Engenharia de Petróleo, Rio de Janeiro: Interciência, Petrobras, 2001; 